\title{
The complex relationship between households' climate change concerns and their water and energy mitigation behaviour
}

\author{
Céline Nauges ${ }^{\mathrm{a}}$ and Sarah Ann Wheeler ${ }^{\mathrm{b}}$
}

\begin{abstract}
a. Toulouse School of Economics, INRA, University of Toulouse Capitole, France
b. Global Food Studies, University of Adelaide, Australia and Adjunct, School of Commerce, University of South Australia, Australia.
\end{abstract}

\begin{abstract}
This study analyses household survey data on water and energy climate change mitigation behaviour from eleven OECD countries in 2011, and provides new evidence of a complex relationship between climate change concerns and mitigation behaviour. Results confirm other studies that climate change concerns positively influence mitigation behaviour. However we also find evidence that this relationship may be more complex in the sense that adoption of mitigation behaviour may in turn change some households' climate change concerns. This effect more likely occurs in 'environmentally-motivated' households. Conversely, economic incentives in driving energy and water mitigation work better in non-environmentally-motivated households. This highlights that a portfolio of policies is needed to drive mitigation behaviour.
\end{abstract}

Key Words: climate change concerns; economic incentives; household data; mitigation behaviour.

\section{Introduction}

To address climate change and reduce carbon footprints, fundamental changes in consumer, producer and industry behaviour will be needed (Adger et al., 2005). There are many social, institutional, cultural, political and technological influences that help shape countries climate change behaviour, which in turn influence subsequent consumer action. Consumer action is important because aspects of daily life, such as heating and cooling homes and patterns of water use, have a significant impact on greenhouse gas emissions (Gardner and Stern, 2008). This study extends the literature on climate 
change concerns and household mitigation behaviour by concentrating on two key areas: water and energy, and seeks to understand further the complex relationship between behaviour and climate change concerns. ${ }^{1}$

\subsection{Determinants of mitigation behaviour}

Previous research (Stern, 2000; Russell and Fielding, 2010; among others) has suggested that there are three key determinants of mitigation behaviour: i) beliefs, attitudes and values; ii) personal capabilities (knowledge, income and time); and iii) contextual influences (country influences, economic incentives and institutions). Individuals' climate change concerns, found to be a reflection of environmental attitudes, national policies, age, personal experience, location, education, gender, political beliefs and income among other factors, are often named as one of the most important influences on mitigation behaviour (e.g. Myers et al., 2012; Zaval et al., 2014; Kaesehage et al., 2014; Lo, 2015). Values held by individuals are also important (e.g. Ajzen, 1991; Dietz et al., 2005; Oreg and Katz-Gerro, 2006) and a distinction is usually made between different types of people, such as altruists, who are more likely to evaluate environmental issues based on the costs or benefits to humanity as a whole; or egoists, who define nature purely in terms of a personal basis; and biospherics who judge environmental issues on the basis of costs or benefits to ecosystems (Milfont et al., 2006). Finally, economic incentives are often found to be an effective policy tool in changing water and energy consumption behaviour (Grafton et al., 2012; Ohler and Billger, 2014; Giles et al., 2014). ${ }^{2}$

There has been much discussion in the psychological and environmental literature about how performing particular forms of behaviour can influence/change people's attitudes and beliefs. This is explained by well-established social psychological consistency theories, such as cognitive dissonance and self-perception theory (e.g. Albarracin and Wyer, 2000; Poortinga et al., 2013). But, we are not aware of any analyses of the possible feedback effect from household mitigation behaviour to climate change concerns (albeit reverse causality has been found between irrigators' climate change concerns and their farm adaptation behaviour (Wheeler et al., 2013)). It is possible that households who invest in expensive mitigation behaviour may consequently feel less concerned. Such evidence exists at the country level: Lo (2015) showed that wealthier countries and countries which have a greater ability to cope with the consequences of climate change are less concerned in general. The presence of a feedback effect from individuals' behaviour to climate change concerns echoes the literature on the so-called 'rebound effect' and the possible adverse and unexpected consequences of incentivising proenvironmental behaviour.

\footnotetext{
${ }^{1}$ Climate change mitigation are actions that involve reductions in human emissions of greenhouse gases, while climate change adaptation are actions that households take in response to climate change.

${ }^{2}$ Attari et al. (2010) also emphasised the importance of individuals' perceived impact of the effectiveness of action on their behaviour.
} 


\subsection{Rebound effect}

The rebound effect suggests that environmentally-friendly adoption to reduce a resource's consumption may lead to a higher demand of that resource (e.g. Santarius, 2012; Peters et al., 2012; Tiefenbeck et al., 2013). This rebound effect is driven by both financial and psychological influences. On the one hand, the financial impact is driven by the relative effects of efficiency gains, price reductions and aggregate demand (Sorrell, 2009; Peters et al., 2012; Tiefenbeck et al., 2013). On the other hand, the psychological influences on the rebound effect, which this study is most interested in, are explained by psychologists as arising from: a) the moral hazard trap: that because the item is more efficient, more of it can be used; b) moral leaking: where one's conscience is appeased and consequently less is cared about the issue overall; and c) moral licensing: where the purchase of proenvironmental technology justifies unfriendly behaviour in another area (Peters et al., 2012; Clot et al., 2014). Other similar terms include guilt reduction, moral cleansing and the warm-glow effect (Tiefenbeck et al., 2013). While there is emerging research investigating how these moral psychological effects impact behaviour, little is known of their magnitude or which populations are more susceptible.

This paper seeks to investigate the issue of the causality relationship between climate change concerns and water and energy mitigation behaviour further using a unique and highly detailed OECD (Organisation for Economic Co-operation and Development) household survey database across eleven countries. Two-way causality (i.e. concerns driving behaviour and behaviour influencing concerns) can be partially tested through the presence of endogeneity in the regression model of interest. ${ }^{3}$ It is important to note that endogeneity may be present for other reasons than a two-way causality relationship, for example because of omitted variables or selection bias. The environmental economics literature has emphasised the importance of the endogeneity of risk perceptions in models describing households' averting decisions: perceived risk about an environmental threat is a driver of averting decisions but averting decisions do, in turn, shape households' risk perceptions (see Bontemps and Nauges (2016) for a discussion of related literature).

\section{Data description}

The data is from a 2011 household survey on Environmental Policy and Individual Behaviour Change conducted by the OECD Environment Directorate (see OECD, 2014). 12,202 households were surveyed in eleven OECD countries: Australia, Canada, Chile, France, Israel, Japan, Korea, the Netherlands, Spain, Sweden and Switzerland. In each country, the online survey sample was stratified

\footnotetext{
${ }^{3}$ Technically, in a statistical model of the form $\mathrm{Y}=\mathrm{X} \beta+\mathrm{e}$, endogeneity arises when the $\mathrm{X}$ variable is correlated with the error term e.
} 
according to age, gender, income and region. Households were surveyed on their opinions, attitudes and behaviour related to the environment in five areas: waste recycling, water use, energy use, transportation, and food. ${ }^{4}$ The main variable of interest in this study is respondents' climate change concerns, which are measured on a scale from 0 (climate change is not serious at all) to 10 (climate change is extremely serious). We assess its influence on households' mitigation behaviour in the water and energy domains and test for a possible feedback effect (that is, the possibility that behaviour could in turn influence climate change concerns). Definitions and summary statistics are shown in Table 1.

One important aspect that needs considering when modelling mitigation behaviour is the cost of such behaviour. By cost we mean both the dollar cost of buying/installing a certain technology or product and also the opportunity cost of the time involved by households to install an equipment or adopt some behaviour. Some behavioural household change (e.g. curtailing habits) is very low cost in terms of financial outlays, while other behavioural change (e.g. adoption of efficiency-improving solar panels) is very high cost (Hawcroft and Milfont, 2010). This study adopts Gardner and Stern (2008) terminology of 'curtailment mitigation' (using equipment less frequently or intensively) and 'efficiency-improving mitigation' (e.g. installation of more efficient equipment) to delineate mitigation behaviour into two groups (primarily low-cost versus high-cost adoption). ${ }^{5}$

Four measures of household mitigation behaviour are built: two curtailment behaviour indexes, one each for water and energy, that account for habits/routines or behaviour that does not cost much in terms of time or money (Table 2). Curtailment indexes include actions such as turning off lights when leaving a room and watering the garden in the coolest part of the day to reduce evaporation, for the energy- and water-related indexes respectively. Two efficiency-improving behaviour indexes are built that account for adoption of costly water-saving and energy-saving equipment/technology such as dual-flush toilets or energy-efficient windows. Our indexes do not necessarily represent the 'ease' of adoption. For example, it may be easier for some households to install costly solar panels than it is to change their habits to turn off lights. All four indexes are standardised between 0 and 100. In all cases, a higher index value indicates that households have adopted greater mitigation actions. It is important to note that from a household perspective (but not necessarily from a nation perspective), adopting efficiency-improving mitigation is more effective than curtailment mitigation (e.g. Gardner and Stern, 2008).

\footnotetext{
${ }^{4}$ This article first attempted to analyse all five areas of behaviour. Due to measurement issues for some areas (food and waste), space constraints, the synergy between energy and water behaviour and the fact that energy behaviour contributes the most to reducing greenhouse gas emissions (Gardner and Stern, 2008), we ended up focussing on water and energy.

${ }^{5}$ Gardner and Stern (2008) argued that efficiency-improving actions are more effective mitigation tools than curtailment actions (in the sense the one-off purchase has immediate lasting effects of reducing emissions while curtailment actions must be repeated continuously over time). But, it is important to note that both types of mitigation behaviour are seen as important in reducing greenhouse gas emissions because if curtailment mitigation behaviour is more widely adopted than efficiencyimproving mitigation it may lead to greater reduction of emissions overall (Attari et al., 2010).
} 


\section{Table 1. Definitions and summary statistics}

\section{Table 2. Water and energy curtailment and efficiency-improving indexes}

In order to allow for possible differences between households with different intrinsic motivations, we distinguish between environmentally-motivated households and the rest (includes environmental sceptics, technological optimists and extreme responders). These classes were defined by the OECD following the application of a clustering methodology (see Appendix A1). Environmentally-motivated households ( $46 \%$ of the sample) believe that climate change exists and that human actions can help mitigate the negative consequences of climate change. The rest (non-environmentally motivated) undertake pro-environmental actions for a variety of other reasons, including financial motives. Comparing the average statistics of the households, environmentally-motivated respondents are more likely to have more children, a lower income, rent, live in urban/suburban areas, be female, younger and a member of charity organizations (Table A2 in Appendix). Table 3 depicts the average of the four behavioural indexes; climate change concerns and the proportion of environmentally-motivated households in each country.

Table 3. Country-average water and energy adoption behaviour indexes (0-100 scale), climate change (CC) concerns (0-10 scale), and proportion of environmentally-motivated households

Respondents from the Netherlands and Australia are the least concerned about climate change while the average level of concerns is at its highest in Korea and Chile. The proportion of environmentallymotivated households varies from $28 \%$ in the Netherlands to $64 \%$ in Israel. Adoption of curtailment behaviour in both the water and energy domains is quite widespread in all countries; most of the average curtailment indexes being above 75 . Adoption of efficiency-improving equipment was less common (indexes generally ranged from $30-40$ ).

\section{Methodology}

A number of studies have estimated the impact of households' perceived risk on the adoption of averting actions. In the environmental economics literature it is now well recognized that both actual risk and perceived risk cannot be treated as exogenous variables in regression models explaining households' averting decisions (Bontemps and Nauges, 2016). This is for the main reason that actual and perceived risks depend on the actual level of safety faced by the household, itself being conditional on averting actions being undertaken. In such regression settings where the causality goes both ways (perceptions causing actions and actions influencing perceptions), usual regression techniques such as (one-stage) Ordinary Least Squares (OLS) produce flawed estimates and other, more appropriate, econometric techniques are required in order to get accurate measures of impacts. A simultaneity problem could also occur when measuring the impact of climate change concerns on 
households' mitigation actions. In order to account for the possibility that households' level of concerns may be partly driven by their actions, we employ the 'control function approach' that is robust to such a simultaneity problem (also known as endogeneity bias) (see Woolridge, 2010, for greater details).

The model of interest describing household $i$ 's adoption of mitigation behaviour $j$ (where $j$ varies from 1 to 4 and represents the four curtailment and efficiency-improving water- and energy-saving behaviours) is written as follows:

ENVIND $_{i j}=\alpha_{j}$ CCConcern $_{i}+\mathbf{X}_{\mathbf{i j}}^{\prime} \boldsymbol{\beta}_{\mathbf{j}}+u_{i j}$, for $\mathrm{j}=1, \ldots, 4$,

where ENVIND is the behavioural index, CC concerns is the variable measuring respondents' concerns about climate change, $\mathbf{X}$ is the vector of exogenous variables (including a constant term), $\alpha_{j}$ and $\boldsymbol{\beta}_{\mathbf{j}}$ are unknown parameters to be estimated, and $u_{i j}$ is the error term. The exogenous variables were chosen from the literature review, and the available questions asked in the OECD survey (see Table 1) and any other regional area information that was available. The model also includes country dummies that control for all unobserved country-specific characteristics. The latter may include various country specificities such as average climate, institutions, overall level of environmental concerns, cultural aspects etc. In order to test and control for endogeneity bias, the following equation is specified:

CCconcern $_{i}=\mathbf{X}_{\mathrm{ij}}^{\prime} \theta_{\mathbf{j}}+\mathbf{Z}_{\mathbf{i}}^{\prime} \mathbf{\kappa}+\varepsilon_{i j}$, for $\mathbf{j}=1, \ldots, 4$.

In Model (2) climate change concerns becomes the dependent variable and is regressed on the set of exogenous variables $(\mathbf{X})$ and a vector of instruments $(\mathbf{Z})$. Instruments should be such that they are correlated with climate change concerns (CC concerns), and uncorrelated with both the behavioural index $(E N V I N D)$ and the error term in the main equation $\left(u_{i j}\right)$.

The 'control function' approach is as follows: estimate Model (2) using OLS and obtain the residuals $\hat{\varepsilon}_{i j}$. In the second-stage an augmented version of Model (1), which includes the estimated first-stage residuals as an additional explanatory variable, is estimated by OLS:

ENVIND $_{i j}=\alpha_{j}$ CCConcern $_{i}+\mathbf{X}_{\mathbf{i j}}^{\prime} \boldsymbol{\beta}_{\mathbf{j}}+\chi \hat{\varepsilon}_{i j}+\omega_{i j}$, for $\mathrm{j}=1, \ldots, 4$.

Under the assumption that $\mathbf{Z}$ are valid instruments, then the OLS estimation of Model (3) provides unbiased estimates of $\alpha_{j}, \boldsymbol{\beta}_{\mathbf{j}}$ and $\chi$. The extra term which enters additively in Model (3), $\chi \hat{\varepsilon}_{i j}$, is called the 'control function' and is used to test and correct for endogeneity. A rejection of the null assumption that $\chi=0$ would be evidence for endogeneity of the variable measuring climate change 
concerns and a positive [resp. negative] $\chi$ coefficient would indicate that the impact of climate change concerns on households' mitigation behaviour is under-estimated [resp. over-estimated] if endogeneity is not controlled for with appropriate techniques. Because the control-function approach involves two steps, bootstrap techniques are used in the second-stage to obtain accurate standard errors of the estimated coefficients.

The application of the method described above relies on the choice of variables that meet the definitions of valid instruments. Such variables are difficult to find, because most variables that have an effect on the endogenous variable (here climate change concern) may also have a direct effect on the variable to be explained (here mitigation behaviour). Instruments validity can only be assessed through a series of tests, which include checking for both under- and over-identification of the model and a test for the possible weakness of the instruments: a model is said to be under-identified when the instruments are not correlated with the endogenous regressor, and over-identified when the instruments are uncorrelated with the error term and correctly excluded from the estimated equation; instruments would be considered weak if they are only weakly correlated with the endogenous variable.

We found three instruments that passed these tests, hence can be confidently used to measure and correct for endogeneity bias. The first instrument was the respondent's opinion on trustworthiness with regard to information on claims about the environmental impact of products, coming from researchers, scientists, and experts. It was measured from a scale varying from 0 (not at all trustworthy) to 10 (very trustworthy). The second instrument was the respondent's average level of satisfaction towards their local environment including air quality, water quality (in lakes, rivers, sea), access to green spaces, level of noise, and management of litter and rubbish. For each of these five items the respondent indicated their level of satisfaction on a five-degree scale. The proposed instrument is an index equal to the average of the five scores. The third instrument is the country Environmental Performance Index (EPI - for greater details see http://epi.yale.edu/). This 0-100 index includes measures of protection of human health (e.g., child mortality, air pollution, access to drinking water and sanitation) and protection of ecosystems (e.g., wastewater treatment, pesticide regulation, changes in forest cover, fish stocks, carbon intensity trends).

\section{Results}

Table 4 presents the outcomes of eight regression models. The dependent variables are the four behavioural indexes representing adoption of curtailment and efficiency-improving mitigation for water and energy-related items. The regression models featuring these four adoption indexes as dependent variables are estimated separately for the group of environmentally-motivated households 
versus the other households. ${ }^{6}$ The estimated coefficients obtained using the two-stage control function approach and their level of statistical significance are reported. The coefficients in the eight columns measure the marginal effect of a change in each explanatory variable on the corresponding $0-100$ index. First-stage model results are not shown but are available upon request. The three instruments were found to be highly significant in all cases: a higher trust in experts' opinion, a lower satisfaction about the quality of the local environment, and a lower country EPI increase respondent's perception of the seriousness of climate change.

\section{Table 4. Results for energy and water curtailment and efficiency-improving mitigation behaviour; by household type}

Our key results confirm that, in general, increases in climate change concerns impact positively on household mitigation behaviour, but we find some heterogeneity in the magnitude of the impact. For environmentally-motivated households, climate change concerns increases adoption of water and energy efficiency-improving mitigation, and adoption of water curtailment mitigation (the coefficient of climate change concerns is not statistically significant in the model describing adoption of energy curtailment). For those households, the marginal effect of climate change concerns (i.e., a one-unit increase on the 0-10 scale measuring concern) increases the index measuring water efficiencyimproving mitigation by 3.4 points (on a $0-100$ scale) on average and the index of energy efficiencyimproving mitigation by 4.3 points on average. The marginal effect of climate change concerns on water curtailment mitigation is lower, estimated at 1.1 on average. For the other group of households, we find evidence that being more concerned about climate change also increases the number of curtailment mitigation actions undertaken in both the water and energy domains (marginal effects estimated at $0.8-0.9$ on average), and the number of water efficiency-improving mitigation actions (marginal effect estimated at 1.3 on average).

We find evidence of endogeneity of the variable measuring climate change concerns in the models describing adoption of efficiency-increasing mitigation by the environmentally-motivated households in both the water and energy areas. In these two models (columns 5 and 7 in Table 4), the coefficient of the control function, $\chi$, is found negative and statistically significant. This result indicates that the impact of climate change concerns on adoption of efficiency-increasing mitigation by environmentally-motivated households would be over-estimated if endogeneity was not controlled for.

There are two main possible drivers of endogeneity in this model: first, and as explained earlier, a two-way causal relationship could be driving endogeneity if the adoption of increasing-efficiency

\footnotetext{
${ }^{6} \mathrm{We}$ also re-estimated the models on the sub-sample of homeowners only because renters may not always have the possibility or opportunity to undertake increasing-efficiency actions. The main results and conclusions were found to be on the whole similar to Table 4 results (additional analysis available upon request).
} 
actions was (in turn) altering the level of household concerns. In this case, because the $\chi$ coefficient has a negative sign, this would suggest that the adoption of increasing-efficiency actions induces environmentally-motivated households to become less concerned about climate change. This could happen if households who invest in expensive mitigation behaviour feel less concerned as a consequence, possibly through the presence of moral leaking or licensing effects. Another possible source of endogeneity is the unobservability of important variables in our model. If some unobserved variables drive both climate change concerns and households' mitigation actions, then this will also produce an endogeneity bias. Unfortunately, because our data are only cross-sectional (i.e., collected at a single point in time), we are unable to identify whether a bi-directional causality or/and the omission of important variables are the main drivers of endogeneity. However, given that there is statistical evidence of an endogeneity bias only for the sub-group of environmentally-motivated households who engaged in energy and water efficiency-improving mitigation, we believe it is more likely to originate from the two-way causality. Indeed if endogeneity was caused by omitted variables, we would expect it to be present for both types of households and both types of mitigation behaviour.

Our results across eleven OECD countries indicate that in terms of driving household mitigation behaviour, economic incentives induce efficiency-improving energy mitigation only for the nonenvironmentally-motivated. This is similar to Clot et al. (2014) who found (in experiments) that regulation did not work well on environmentally-motivated individuals but it did work well with other non-intrinsically motivated individuals. Economic incentives are also a much stronger influence on energy curtailment mitigation behaviour of the non-environmentally motivated. However, water pricing economic incentives positively influence both water efficiency-improving and curtailment mitigation of both environmentally and non-environmentally motivated households.

In addition, it seems that it is higher household income that enables environmentally-motivated households to adopt efficiency-improving energy mitigation, while it is the cost of energy/economic incentives that is the more relevant driving factor for non-environmentally motivated households. Higher household income is a negative influence on curtailment behaviour: poorer households are much more likely to be careful about energy and water-use than richer households. Therefore, having a higher income may allow environmentally-motivated households to 'buy' their way out feeling guilty over using a lot of energy or water by investing in efficiency-improving mitigation. Poorer households, on the other hand, address their climate change concerns by undertaking more curtailment mitigation behaviour.

Finally our results indicate that charity involvement, which may be related to altruistic values, is strongly positively correlated with the number of efficiency-improving and curtailment mitigation actions undertaken by both groups of households. 


\section{Discussion and conclusion}

Using a household survey covering eleven OECD countries, we confirmed that a) households' climate change concerns do positively impact on mitigation behaviour and b) economic incentives are positive significant influences on mitigation behaviour. We also found new evidence that the relationship between concerns and behaviour may be more complex in the sense that the causality may go both ways. This effect (revealed through endogeneity tests) occurs primarily for efficiency-improving mitigation and in households that hold certain environmental values, namely environmentallymotivated households who believe human actions can help mitigate climate change. As a result it seemed there was a lessening of climate change concerns after taking mitigation action, possibly because of the presence of the moral leaking or the moral licensing effect. However, we have to remain cautious in interpreting this result since endogeneity may also originate from the presence of omitted variables. Unfortunately, the cross-sectional form of our data does not allow us to further investigate the two-way causality relationship. However, given that the feedback effect statistically significantly occurred mainly in environmentally-motivated households who engaged in energy and water efficiency-improving mitigation and nowhere else, we believe it seems more likely that this is a moral leaking or licensing effect than an omitted variable effect. Further experiments or panel datasets that follow households' concerns and behaviour over time would be needed to explore this relationship further.

Our results also show that households' mitigation behaviour as a response to climate change concerns and economic incentives vary across households' types. Albeit, the OECD data only allowed us to test very basic water and electricity charging across regions and countries, it is not possible to say whether more sophisticated pricing schemes (e.g. as outlined for water in California by Baerenklau et al., 2014) would work in incentivising households who hold such environmental values.

Even in the face of such feedback effects we believe that there is cause to be positive as there are tools available to change people's behaviour. But, no-one policy choice (e.g. regulation; economic incentives; or education) will be the answer; a portfolio of targeted incentives and information is needed. Economic incentives (e.g., pricing, subsidies and taxes) can play a significant and positive role, especially when households do not have any intrinsic motivation to take pro-environmental actions. For different population cohorts, sustainability education, environmental awareness, emphasising the co-benefits of increased action (Bain et al., 2015) and environmental messaging about avoiding overestimating benefits (Clot et al., 2014) may be some of the best ways to change behaviour and limit the feedback effect, especially when that behaviour includes very costly actions. Further consideration of a portfolio of approaches will be needed. In some countries (e.g. particularly developed countries), information on households is readily available, which makes it easier and cost- 
effective to implement such strategies, as compared to other countries where implementing a mix of policies is more difficult.

\section{Acknowledgements}

The constructive comments from four referees is gratefully acknowledged. 
Table 1. Definitions and summary statistics

\begin{tabular}{|c|c|c|c|}
\hline Variables definitions & Mean & Min & Max \\
\hline $\begin{array}{l}\text { Respondent's ranking of climate change seriousness on a scale from } 0 \text { (not at all } \\
\text { serious) to } 10 \text { (extremely serious). }\end{array}$ & 7.62 & 0 & 10 \\
\hline Respondent's gender: takes the value 1 if the respondent is a male, and 0 otherwise. & 0.49 & 0 & 1 \\
\hline Respondent's age measured in number of years. & 42 & 18 & 69 \\
\hline $\begin{array}{l}\text { Respondent's education: takes the value } 1 \text { if the respondent completed one or more } \\
\text { years of education after high school, and } 0 \text { otherwise. }\end{array}$ & 0.79 & 0 & 1 \\
\hline $\begin{array}{l}\text { Respondent's employment status: takes the value } 1 \text { if the respondent is either an } \\
\text { employee or self-employed, and } 0 \text { if he/she is retired, homemaker, unemployed, } \\
\text { student, or unable to work. }\end{array}$ & 0.63 & 0 & 1 \\
\hline Household's size: number of household members. ${ }^{a}$ & 2.89 & 1 & 5 \\
\hline Number of household members who are below 18 years of age. ${ }^{a}$ & 0.64 & 0 & 5 \\
\hline Household annual after tax income in thousand euros. ${ }^{b}$ & 37.9 & 2.3 & 159.1 \\
\hline $\begin{array}{l}\text { Ownership status: takes the value } 1 \text { if the respondent or a member of his/her } \\
\text { household owns the current primary residence, and } 0 \text { otherwise. }\end{array}$ & 0.63 & 0 & 1 \\
\hline $\begin{array}{l}\text { Location: takes the value } 1 \text { if the household lives in a major town/city or in a } \\
\text { suburban area, and } 0 \text { otherwise. }\end{array}$ & 0.66 & 0 & 1 \\
\hline $\begin{array}{l}\text { Type of residence: takes the value } 1 \text { if the household lives in a detached or semi- } \\
\text { detached/terraced house, and } 0 \text { otherwise. }\end{array}$ & 0.54 & 0 & 1 \\
\hline $\begin{array}{l}\text { Life satisfaction index: respondent's ranking of his/her satisfaction with life at the } \\
\text { moment from } 0 \text { (very dissatisfied) to } 10 \text { (very satisfied). }\end{array}$ & 6.39 & 0 & 10 \\
\hline $\begin{array}{l}\text { Respondent's involvement in charitable organisations: takes the value } 1 \text { if the } \\
\text { respondent has supported or participated in the activities of charitable organisations } \\
\text { (includes membership, personal time, and/or financial donations), and } 0 \text { otherwise. }\end{array}$ & 0.27 & 0 & 1 \\
\hline $\begin{array}{l}\text { Electricity charge: takes the value } 1 \text { if the household pays for electricity according } \\
\text { to how much electricity is used, and } 0 \text { otherwise. }\end{array}$ & 0.91 & 0 & 1 \\
\hline $\begin{array}{l}\text { Water charge: takes the value } 1 \text { if the household pays for water according to how } \\
\text { much water is used, and } 0 \text { otherwise }\end{array}$ & 0.73 & 0 & 1 \\
\hline $\begin{array}{l}\text { Trust in experts: respondent's opinion on trustworthiness with regard to information } \\
\text { on claims about the environmental impact of products, coming from researchers, } \\
\text { scientists, and experts, on a scale from } 0 \text { (not at all trustworthy) to } 10 \text { (very } \\
\text { trustworthy). }\end{array}$ & 7.01 & 0 & 10 \\
\hline $\begin{array}{l}\text { Local environment satisfaction index: respondent's average level of satisfaction } \\
\text { towards air quality, water quality (in lakes, rivers, sea), access to green spaces, level } \\
\text { of noise, and management of litter and rubbish in his/her local environment }{ }^{\mathrm{c}}\end{array}$ & -0.15 & -2 & 1.8 \\
\hline
\end{tabular}

\footnotetext{
a The variable was set equal to 5 if the respondent answered "five or more".

${ }^{\mathrm{b}}$ Respondents were asked to choose one of 10 income intervals (intervals were adjusted for each country in order to ensure a reasonable distribution across the different bands). Responses were then converted into a continuous income variable: midpoints were taken for the eight intermediate intervals and non-linear curves were fit for each country in order to generate the values for the lowest and highest income bands.

${ }^{c}$ For each of these five items the respondent had to indicate its level of satisfaction on a five-degree scale: -2 (very dissatisfied), -1 (dissatisfied), 0 (no opinion), 1 (satisfied), and 2 (very satisfied). The index is the average of the five scores.
} 
Table 2. Water and energy curtailment and efficiency-improving indexes

\begin{tabular}{|c|c|c|c|}
\hline \multicolumn{2}{|c|}{ Water } & \multicolumn{2}{|c|}{ Energy } \\
\hline Curtailment $^{a}$ & Efficiency-improving $^{b}$ & Curtailment $^{a}$ & Efficiency-improving $^{b}$ \\
\hline $\begin{array}{l}\text { - turning off the water } \\
\text { while brushing teeth; } \\
\text { - plugging the sink when } \\
\text { washing the dishes by } \\
\text { hand; } \\
\text { - watering the garden in } \\
\text { the coolest part of the } \\
\text { day to reduce } \\
\text { evaporation and save } \\
\text { water; } \\
\text { collecting rainwater or } \\
\text { recycling waste water; } \\
\text { - rinsing dishes before } \\
\text { putting them in the } \\
\text { dishwasher; } \\
\text { - taking showers instead } \\
\text { of baths. }\end{array}$ & $\begin{array}{l}\text { Current adoption of the } \\
\text { following: } \\
\text { - low volume or dual } \\
\text { flush toilets; } \\
\text { - water flow restrictor } \\
\text { taps/low flow shower } \\
\text { heads; } \\
\text { - water tank to collect } \\
\text { rainwater. }\end{array}$ & $\begin{array}{l}\text { turning off lights when } \\
\text { leaving a room; } \\
\text { cutting down on } \\
\text { heating/air } \\
\text { conditioning to limit } \\
\text { energy consumption; } \\
\text { only running full loads } \\
\text { when using washing } \\
\text { machines or } \\
\text { dishwashers; } \\
\text { washing clothes using } \\
\text { cold water rather than } \\
\text { warm/hot water; } \\
\text { switching off standby } \\
\text { mode of appliances/ } \\
\text { electronic devices; } \\
\text { using air-dry laundry } \\
\text { rather than a clothes } \\
\text { dryer. }\end{array}$ & $\begin{array}{l}\text { Current adoption of the } \\
\text { following: } \\
\text { - top rated energy- } \\
\text { efficient appliances; } \\
\text { - low-energy light bulbs; } \\
\text { - energy-efficient } \\
\text { windows; } \\
\text { - thermal insulation of } \\
\text { walls/roof; } \\
\text { - heat thermostats; } \\
\text { - solar panels for } \\
\text { electricity of hot water; } \\
\text { - wind turbines; } \\
\text { - ground-source heat } \\
\text { pumps. }\end{array}$ \\
\hline
\end{tabular}

${ }^{a}$ For each of these two low-cost habits, household gets a score of 1 if it never performs it, 2 if it performs it occasionally, 3 if it performs it often, and 4 if it always performs it. A missing value indicates that the question was not relevant. The index is the mean of scores calculated over the number of non-missing responses.

${ }^{b}$ Both indexes are based on the household's adoption of relevant equipment/devices over the past ten years. For each of these items, household gets a score of 1 if it has been installed in its current primary residence over the last ten years, and 0 otherwise. The score is set to missing if installation of the equipment was not possible (for example because the household is renting its residence and only the landlord could install the equipment). The index is the mean of scores calculated over the number of non-missing responses.

Table 3. Country-average water and energy adoption behaviour indexes (0-100 scale), climate change (CC) concerns (0-10 scale), and proportion of environmentally-motivated households

\begin{tabular}{lcccccc}
\hline \multicolumn{2}{c}{ Energy } & \multicolumn{2}{c}{ Water } \\
& Curtailment & $\begin{array}{c}\text { Efficiency- } \\
\text { improving }\end{array}$ & Curtailment & $\begin{array}{c}\text { Efficiency- } \\
\text { improving }\end{array}$ & $\begin{array}{c}\text { CC } \\
\text { concern }\end{array}$ & $\begin{array}{c}\text { Env- } \\
\text { motivated }\end{array}$ \\
\hline Australia & 84 & & & & & \\
Canada & 78 & 37 & 86 & 47 & 6.88 & 0.42 \\
Chile & 87 & 42 & 77 & 36 & 7.35 & 0.46 \\
France & 85 & 26 & 72 & 26 & 8.87 & 0.54 \\
Israel & 82 & 42 & 83 & 48 & 7.40 & 0.56 \\
Japan & 78 & 30 & 70 & 41 & 7.93 & 0.64 \\
Korea & 84 & 36 & 58 & 17 & 7.54 & 0.30 \\
Netherlands & 78 & 37 & 77 & 20 & 8.77 & 0.38 \\
Spain & 88 & 37 & 78 & 43 & 6.60 & 0.28 \\
Sweden & 67 & 39 & 74 & 36 & 7.95 & 0.37 \\
Switzerland & 76 & 38 & 75 & 32 & 7.21 & 0.55 \\
\hline
\end{tabular}


Table 4. Results for energy and water curtailment and efficiency-improving mitigation behaviour; by household type

\begin{tabular}{|c|c|c|c|c|c|c|c|c|}
\hline \multirow{2}{*}{$\begin{array}{l}\text { Adoption type } \\
\text { Household cluster }\end{array}$} & \multicolumn{2}{|c|}{ Energy curtailment } & \multicolumn{2}{|c|}{$\begin{array}{c}\text { Water } \\
\text { curtailment }\end{array}$} & \multicolumn{2}{|c|}{$\begin{array}{c}\text { Energy efficiency- } \\
\text { improving }\end{array}$} & \multicolumn{2}{|c|}{$\begin{array}{c}\text { Water efficiency- } \\
\text { improving }\end{array}$} \\
\hline & $\begin{array}{l}\text { Env- } \\
\text { mot. }\end{array}$ & Other & $\begin{array}{l}\text { Env- } \\
\text { mot. }\end{array}$ & Other & $\begin{array}{l}\text { Env- } \\
\text { mot. }\end{array}$ & Other & $\begin{array}{l}\text { Env- } \\
\text { mot. }\end{array}$ & Other \\
\hline \multicolumn{9}{|c|}{ Respondent's characteristics } \\
\hline Respondent is a male $^{\dagger}$ & $-2.146^{* * *}$ & $-2.299^{* * *}$ & -0.198 & -0.653 & $-1.702^{* *}$ & -1.069 & -0.538 & $1.821^{*}$ \\
\hline Respondent's age & $0.069^{* * *}$ & $0.035^{* *}$ & $0.141^{* * *}$ & $0.083^{* * *}$ & $0.086^{* * *}$ & $0.085^{* * *}$ & $0.331^{* * *}$ & $0.198^{* * *}$ \\
\hline $\begin{array}{l}\text { Post high-school } \\
\text { education }^{\dagger}\end{array}$ & $0.872^{*}$ & 0.255 & 0.356 & -0.314 & $2.295^{* *}$ & $2.113^{* *}$ & 0.537 & $2.470^{* *}$ \\
\hline Employee status ${ }^{\dagger}$ & 0.076 & $-1.004^{* *}$ & 0.384 & -0.677 & -0.237 & -0.661 & 0.337 & -0.835 \\
\hline Life satisfaction index & $0.153^{*}$ & 0.086 & 0.077 & 0.090 & -0.051 & 0.147 & 0.441 & 0.052 \\
\hline Charity involvement ${ }^{\dagger}$ & $1.026^{* * *}$ & 0.465 & $1.748^{* * *}$ & $2.421^{* * *}$ & $2.676^{* * *}$ & $2.810^{* * *}$ & $4.008^{* * *}$ & $5.413^{* * *}$ \\
\hline Climate change concern & -0.148 & $0.939^{* * *}$ & $1.127^{* *}$ & $0.809^{* * *}$ & $4.288^{* * *}$ & 0.664 & $3.440^{* *}$ & $1.344^{* *}$ \\
\hline Control function & 0.681 & -0.165 & -0.606 & -0.205 & $-3.83^{* * *}$ & -0.329 & $-2.442^{*}$ & -0.847 \\
\hline \multicolumn{9}{|c|}{ Household's (HH) characteristics } \\
\hline HH size & 0.098 & -0.316 & 0.084 & 0.375 & 0.494 & 0.710 & 0.798 & $1.976^{* * *}$ \\
\hline HH members below 18 & 0.290 & 0.153 & 0.414 & 0.017 & $0.977^{*}$ & 0.706 & $1.683^{* *}$ & -0.584 \\
\hline $\mathrm{HH}$ annual income & $-0.043^{* * *}$ & $-0.034^{* * *}$ & $-0.036^{* * *}$ & $-0.033^{* * *}$ & $0.070^{* * *}$ & 0.030 & 0.011 & -0.001 \\
\hline HH ownership $^{\dagger}$ & -0.225 & -0.319 & 0.168 & 0.723 & $-4.186^{* * *}$ & $-3.747^{* * *}$ & $3.071^{* *}$ & $4.684^{* * *}$ \\
\hline Town or suburban area ${ }^{\dagger}$ & 0.248 & 0.012 & 0.085 & $-0.877^{*}$ & -0.145 & -0.700 & 0.995 & -1.562 \\
\hline House $^{\dagger}$ & $0.888^{* *}$ & $1.287^{* * *}$ & $0.865^{*}$ & 0.751 & $-3.860^{* * *}$ & $-2.399^{* * *}$ & $5.292^{* * *}$ & 0.364 \\
\hline \multicolumn{9}{|l|}{ Economic incentives } \\
\hline Electricity charge $^{\dagger}$ & $2.405^{* * *}$ & $3.751^{* * *}$ & - & - & 1.001 & $4.784^{* * *}$ & - & - \\
\hline Water charge $^{\dagger}$ & - & - & $1.889^{* * *}$ & $1.154^{* *}$ & - & - & $4.461^{* * *}$ & $3.937^{* * *}$ \\
\hline \multicolumn{9}{|l|}{ Region } \\
\hline Regional adoption & $0.236^{* *}$ & $0.183^{*}$ & $0.304^{* * *}$ & $0.310^{* * *}$ & 0.071 & $0.368^{* * *}$ & 0.084 & $0.193^{*}$ \\
\hline \multicolumn{9}{|l|}{ Model characteristics } \\
\hline Number of observations & 4,611 & 5,355 & 4,611 & 5,355 & 4,542 & 5,269 & 4,212 & 4,948 \\
\hline R-squared & 0.22 & 0.19 & 0.25 & 0.22 & 0.08 & 0.06 & 0.12 & 0.12 \\
\hline \multicolumn{9}{|c|}{ Tests of instruments validity } \\
\hline $\begin{array}{l}\text { Under-identification test } \\
p \text {-value } \\
\text { Over-identification test } \\
p \text {-value }\end{array}$ & $\begin{array}{l}267.2 \\
0.000 \\
0.139 \\
0.709\end{array}$ & $\begin{array}{l}649.5 \\
0.000 \\
0.244 \\
0.621\end{array}$ & $\begin{array}{l}265.2 \\
0.000 \\
0.499 \\
0.480\end{array}$ & $\begin{array}{l}651.1 \\
0.000 \\
0.063 \\
0.802\end{array}$ & $\begin{array}{l}265.3 \\
0.000 \\
0.036 \\
0.851\end{array}$ & $\begin{array}{l}636.8 \\
0.000 \\
3.256 \\
0.071\end{array}$ & $\begin{array}{l}220.6 \\
0.000 \\
0.002 \\
0.962\end{array}$ & $\begin{array}{l}619.7 \\
0.000 \\
0.066 \\
0.798\end{array}$ \\
\hline
\end{tabular}

${ }^{* * *} p<0.01 ; * * p<0.05 ; * p<0.1{ }^{\dagger}$ indicates the variable takes values 0 and 1 only. Country-specific dummies are not shown here but are available upon request, and are shown in the Appendix's Table A3 full sample results. 


\section{Appendices}

\section{A1. Description of the clustering methodology}

The clustering was performed by the OECD Environment Directorate (for greater details, see OECD, 2014). A latent class analysis was used to identify attitudinal profiles of the respondents. Three major classes were identified based on the respondents' level of agreement (strongly disagree, disagree, agree, strongly agree, no opinion) with the following seven statements about environmental policy: i) Policies introduced by the government to address environmental issues should not cost me extra money; ii) I am willing to make compromises in my current lifestyle for the benefit of the environment; iii) Protecting the environment is a means of stimulating economic growth; iv) Environmental issues will be resolved in any case through technological progress; v) Environmental impacts are frequently overstated; vi) I am not willing to do anything about the environment if others don't do the same; and vii) Environmental issues should be dealt with primarily by future generations. The three classes were labelled by the OECD as: environmentally motivated, environmental sceptics, and technological optimists. Quoting the OECD: "The environmentally motivated comprise just under half of the pooled sample [...]. They believe that environmental problems are real and express a willingness to make compromises in their lifestyle to solve them. Members of this class also expressed the least need for reciprocation from others in order to undertake action to solve environmental problems. Environmental sceptics believe that environmental issues are overstated and do not wish to pay for government environmental policies. But, on the other hand, they do report a general willingness to make compromises for the benefit of the environment, though not to the same degree as the other two substantive classes.

Technological optimists share the belief with the environmentally motivated cluster that environmental problems are real and appear willing to make lifestyles compromises to solve them. The key difference between the two clusters is that the first group expresses a greater belief in the potential of technological progress to solve environmental problems." (OECD, 2014; 67-69). 
A2. Mean characteristics of environmentally-motivated households versus the rest and outcome of mean comparison test

\begin{tabular}{|c|c|c|c|}
\hline Variables $^{\mathrm{a}}$ & Env-motivated & Others & $\begin{array}{c}\text { Significance of } \\
\text { t-test }^{\mathrm{b}}\end{array}$ \\
\hline \multicolumn{4}{|l|}{ Mitigation behaviour } \\
\hline Curtailment - energy & 82 & 80 & $* * *$ \\
\hline Curtailment - water & 76 & 73 & $* * *$ \\
\hline Efficiency-improving - energy & 36 & 34 & $* * *$ \\
\hline Efficiency-improving - water & 37 & 34 & $* * *$ \\
\hline \multicolumn{4}{|l|}{ Respondents' characteristics } \\
\hline Respondent is a male $^{\dagger}$ & 0.40 & 0.56 & $* * *$ \\
\hline Respondent's age & 41.1 & 42.8 & $* * *$ \\
\hline Post high-school education $^{\dagger}$ & 0.79 & 0.78 & n.s. \\
\hline Employee status $^{\dagger}$ & 0.63 & 0.63 & n.s. \\
\hline Life satisfaction index & 6.39 & 6.39 & n.s. \\
\hline Charity involvement $^{\dagger}$ & 0.31 & 0.24 & $* * *$ \\
\hline Climate change concern & 8.4 & 7.0 & $* * *$ \\
\hline \multicolumn{4}{|l|}{ Household's characteristics } \\
\hline Household size & 2.91 & 2.88 & n.s. \\
\hline HH members below 18 & 0.67 & 0.61 & $* * *$ \\
\hline $\mathrm{HH}$ annual income & 36.995 & 38.593 & $* * *$ \\
\hline Ownership of the residence $^{\dagger}$ & 0.61 & 0.64 & $* * *$ \\
\hline Town or suburban area ${ }^{\dagger}$ & 0.67 & 0.65 & $* *$ \\
\hline House $^{\dagger}$ & 0.52 & 0.55 & $* * *$ \\
\hline \multicolumn{4}{|l|}{ Economic incentives } \\
\hline Electricity charge $e^{\dagger}$ & 0.91 & 0.91 & n.s. \\
\hline Water charge $^{\dagger}$ & 0.70 & 0.74 & $* * *$ \\
\hline
\end{tabular}

${ }^{\mathrm{a}} \mathrm{A}^{\dagger}$ following the name of a variable indicates that the variable takes values 0 and 1 only. HH stands for households.

$\mathrm{b} * * * p<0.01 ; * * p<0.05 ;$ n.s. for not significant. 
A3. Estimated coefficients for curtailment and efficiency-improving in energy and water mitigation behaviour; full sample

\begin{tabular}{|c|c|c|c|c|}
\hline \multirow{2}{*}{$\begin{array}{l}\text { Adoption type } \\
\text { Variable }^{a}\end{array}$} & \multicolumn{2}{|c|}{ Energy } & \multicolumn{2}{|c|}{ Water } \\
\hline & Curtailment & Efficiency & Curtailment & Efficiency \\
\hline & Coef. $^{\mathrm{b}}$ & Coef. & Coef. & Coef. \\
\hline \multicolumn{5}{|l|}{ Respondent's characteristics } \\
\hline Respondent is a male ${ }^{\dagger}$ & $-2.392 * * *$ & $-1.133 *$ & -0.488 & 0.653 \\
\hline Respondent's age & $0.048 * * *$ & $0.091 * * *$ & $0.110 * * *$ & $0.266 * * *$ \\
\hline Post high-school education $^{\dagger}$ & $0.541 *$ & $1.980 * * *$ & -0.055 & $1.568 *$ \\
\hline Employee status ${ }^{\dagger}$ & $-0.498 *$ & -0.570 & -0.214 & -0.210 \\
\hline Life satisfaction index & 0.105 & 0.027 & 0.074 & 0.257 \\
\hline Charity involvement $^{\dagger}$ & $0.821 * * *$ & $2.720 * * *$ & $2.180 * * *$ & $4.614 * * *$ \\
\hline Climate change concern & $0.708 * * *$ & $1.639 * * *$ & $0.970 * * *$ & $1.860 * * *$ \\
\hline Control function & 0.050 & $-1.208 * * *$ & -0.316 & $-1.119^{* *}$ \\
\hline \multicolumn{5}{|l|}{ Household's characteristics } \\
\hline Household size & -0.123 & $0.596^{*}$ & 0.212 & $1.445 * * *$ \\
\hline HH members below 18 & 0.256 & $0.821 * *$ & 0.263 & 0.534 \\
\hline $\mathrm{HH}$ annual income & $-0.038 * * *$ & $0.049 * * *$ & $-0.033 * * *$ & 0.000 \\
\hline Ownership of the residence ${ }^{\dagger}$ & -0.164 & $-4.084 * * *$ & 0.542 & $4.153 * * *$ \\
\hline Town or suburban area ${ }^{\dagger}$ & 0.113 & -0.276 & -0.429 & -0.392 \\
\hline House $^{\dagger}$ & $1.026 * * *$ & $-2.794 * * *$ & $0.669 *$ & $2.625 * * *$ \\
\hline \multicolumn{5}{|l|}{ Economic incentives } \\
\hline Electricity charge $^{\dagger}$ & $2.994 * * *$ & $3.119 * * *$ & - & - \\
\hline Water charge $^{\dagger}$ & - & - & $1.563 * * *$ & $4.088 * * *$ \\
\hline \multicolumn{5}{|c|}{ Regional adoption and country dummies } \\
\hline Regional adoption & $0.199 * * *$ & $0.226 * * *$ & $0.292 * * *$ & $0.147 *$ \\
\hline Korea (reference base) & - & - & - & - \\
\hline Australia & $1.967 * * *$ & $4.706 * * *$ & $16.619 * * *$ & $25.737 * * *$ \\
\hline Canada & $-2.794 * * *$ & $7.344 * * *$ & $10.199 * * *$ & $15.524 * * *$ \\
\hline Chile & $2.030 * * *$ & $-5.819 * * *$ & $3.731 * * *$ & 2.509 \\
\hline France & $1.882 * * *$ & $7.269 * * *$ & $14.088 * * *$ & $25.446 * * *$ \\
\hline Israel & -0.772 & $-3.349 * *$ & $3.932 * * *$ & $19.049 * * *$ \\
\hline Japan & $-3.085 * * *$ & $-8.623 * * *$ & $-3.710 * * *$ & -1.983 \\
\hline Netherlands & $-3.513 * * *$ & $5.709 * * *$ & $9.281 * * *$ & $22.335 * * *$ \\
\hline Spain & $3.725 * * *$ & $2.071^{*}$ & $9.644 * * *$ & $13.975 * * *$ \\
\hline Sweden & $-12.287 * * *$ & $5.794 * * *$ & $7.923 * * *$ & $13.844 * * *$ \\
\hline Switzerland & $-3.802 * * *$ & 0.791 & $9.222 * * *$ & $17.728 * * *$ \\
\hline No. of obs. & 10,155 & 9,979 & 10,151 & 9,326 \\
\hline R-squared & 0.2033 & 0.0671 & 0.2268 & 0.1138 \\
\hline
\end{tabular}

Tests of instruments validity

Under-identification test

$1163.23 * * * \quad 1144.36 * * * \quad 1157.65 * * * \quad 1060.76 * * *$

Over-identification test

0.012

1.155

0.376

0.000

${ }^{\mathrm{a}} \mathrm{A}^{\dagger}$ following the name of a variable indicates that the variable takes values 0 and 1 only. $\mathrm{HH}$ stands for households.

$\mathrm{b} * * * p<0.01 ; * * p<0.05 ; * p<0.1$. 